\title{
A novel polishing stop for accurate integration of potassium yttrium double tungstate on a silicon dioxide
}

Carlijn I. van Emmerik, Simen M. Martinussen, Jinfeng Mu, Meindert Dijkstra, Roy Kooijman, et al.

Carlijn I. van Emmerik, Simen M. Martinussen, Jinfeng Mu, Meindert Dijkstra, Roy Kooijman, Sonia M. García-Blanco, "A novel polishing stop for accurate integration of potassium yttrium double tungstate on a silicon dioxide," Proc. SPIE 10535, Integrated Optics: Devices, Materials, and Technologies XXII, 105350 U (23 February 2018); doi: 10.1117/12.2289955

SPIE. Event: SPIE OPTO, 2018, San Francisco, California, United States 


\title{
A novel polishing stop for accurate integration of potassium yttrium double tungstate on silicon dioxide
}

\author{
Carlijn I. van Emmerik*a , Simen M. Martinussen ${ }^{\mathrm{a}}$, Jinfeng Mu', Meindert Dijkstra ${ }^{\mathrm{a}}$, Roy Kooijman ${ }^{\mathrm{b}}$, \\ Sonia M. García-Blanco ${ }^{a}$ \\ ${ }^{a}$ Optical Sciences, MESA+ Institute for Nanotechnology, University of Twente, 7500 AE Enschede, \\ The Netherlands; ${ }^{\mathrm{b}}$ Techno Centrum for Onderwijs en Onderzoek, Glas instrumentmakerij, \\ University of Twente, Drienerlolaan 5, 7522 NB, Enschede The Netherlands \\ *c.i.vanemmerik@utwente.nl; phone+31 53489 2569; os.tnw.utwente.nl
}

\begin{abstract}
Rare-earth ion doped potassium yttrium double tungstate, RE: $\mathrm{KY}\left(\mathrm{WO}_{4}\right)_{2}$, is a promising candidate for the realization of on-chip lasers and amplifiers. Two major bottlenecks difficult the realization of compact, high-contrast devices. Firstly, the crystal can only be grown on a lattice matched substrate, leading to a low $\left(<2 \cdot 10^{-2}\right)$ refractive index contrast between core and cladding. Secondly, the required thickness for the high-index contrast waveguides, $\sim 1 \mu \mathrm{m}$, makes a lapping and polishing approach very challenging. In this work we propose a novel polishing stop that will permit to accurately control the final thickness of the $\mathrm{KY}\left(\mathrm{WO}_{4}\right)_{2}$ waveguide within a few tens of nanometers. A $1 \mathrm{~mm}$ thick $\mathrm{KY}\left(\mathrm{WO}_{4}\right)_{2}$ substrate is flip-chip bonded with an adhesive layer onto a $\mathrm{SiO}_{2}$ substrate. Afterwards a low temperature pulsed laser deposited (PLD) $\mathrm{Al}_{2} \mathrm{O}_{3}$ layer - with the desired final thickness of the $\mathrm{KY}\left(\mathrm{WO}_{4}\right)_{2}$ waveguide core - is deposited on top of the assembly. The sample is then thinned using a multistep lapping and polishing procedure. Earlier work with a polishing stop made from $\mathrm{SiO}_{2}$, showed a decrease of the polishing speed with a factor 3-4, allowing the termination of the process within a tolerance of a few tens of nanometers.
\end{abstract}

Keywords: integrated optics, heterogeneous integration, potassium double tungstate, bonding, lapping, polishing.

\section{INTRODUCTION}

Rare-earth ion doped potassium yttrium double tungstate, $\mathrm{RE}: \mathrm{KY}\left(\mathrm{WO}_{4}\right)_{2}$ is recognized as a promising material for onchip lasers and amplifiers. This crystal has a relatively high refractive index $(\mathrm{n} \approx 2.00 @ 1550 \mathrm{~nm}$ [1]) compared to other materials used in integrated optics, like $\mathrm{SiO}_{2}$ or $\mathrm{Al}_{2} \mathrm{O}_{3}$. Furthermore it exhibits a large interionic spacing $(<\mathrm{d}>\approx 0.5 \mathrm{~nm}$ [2]) which allows high doping concentrations of rare-earth ions before clustering occurs. Additionally, the large emission and absorption cross-sections for rare-earth ions doped into this host material [3] makes efficient pumping possible in combination with small waveguide mode sizes.

Previous studies have demonstrated waveguide amplifiers with a modal gain of $\sim 1000 \mathrm{~dB} / \mathrm{cm}$ at a wavelength of $980 \mathrm{~nm}$ [4], lasers at $\sim 1 \mu \mathrm{m}$ wavelength with large tuning bandwidth [5],[6] and highly efficient high power thulium doped waveguide lasers emitting around $2 \mu \mathrm{m}(1.6 \mathrm{~W}$ of output power with over $80 \%$ slope efficiency [7]) grown using liquid phase epitaxy of doped layers onto undoped seed crystals. This method leads to a low $(\Delta n<0.02$ [8]) refractive index contrast between core and cladding. Relatively high pump powers are therefore necessary to invert the material. High index contrast waveguides are expected to reduce the pump power requirement, leading to highly efficient on-chip amplifiers and lasers. Furthermore, the high field confinement in such waveguides will make possible to benefit from the excellent non-linear properties of this material to produce very efficient non-linear devices.

$\mathrm{KY}\left(\mathrm{WO}_{4}\right)_{2}$ layers cannot be grown directly on low refractive index substrates such as $\mathrm{SiO}_{2}$ due to lattice mismatch. Heterogeneous integration is the preferred approach for the integration of $\mathrm{KY}\left(\mathrm{WO}_{4}\right)_{2}$ onto low refractive index substrates to form high-index contrast waveguides. For the heterogeneous integration a bulk $\mathrm{KY}\left(\mathrm{WO}_{4}\right)_{2}$ crystal is bonded on $\mathrm{SiO}_{2}$ substrate and subsequently thinned to the required thickness using various lapping and polishing steps. Sefunç et al. [9] demonstrated heterogeneously integrated $\mathrm{KY}\left(\mathrm{WO}_{4}\right)_{2}$ rib waveguides for the first time. Those waveguides where patterned using focus ion beam milling (FIB) on a $2.4 \mu \mathrm{m}$ thick $\mathrm{KY}\left(\mathrm{WO}_{4}\right)_{2}$ layer. However, FIB milling is not the optimal approach for long devices due the limited writing field. Standard lithography followed by 
reactive ion etching are more scalable techniques. However, the layer thickness has to be controlled within tens of nanometers to guarantee uniform performance of the devices. Such uniformity cannot be achieved with the current process.

In previous work [10] we demonstrated the first version of a novel integrated polishing stop to obtain a thin $\mathrm{KY}\left(\mathrm{WO}_{4}\right)_{2}$ layer. A pool was etched in a $\mathrm{SiO}_{2}$ substrate and the bulk $\mathrm{KY}\left(\mathrm{WO}_{4}\right)_{2}$ crystal was then bonded with $\mathrm{UV}$ curable adhesive into this pool. Afterwards an extensive lapping and polishing procedure was performed until the surface of the $\mathrm{SiO}_{2}$ substrate, the polishing stop, was reached. At that point, the polishing speed diminished by a factor of 3-4. This approach increased the tolerance of the process. However, the planarity of the layer could not be ensured over the entire surface area of the substrate. In this work, we demonstrate a new version of the polishing stop, which improves the planarity and controllability of the final thickness of the layer.

\section{HETEROGENEOUS INTEGRATION WITH POLISHING STOP}

There are numerous reports of heterogeneous integration of III-V materials on dielectric substrates using different bonding techniques. Adhesive bonding with BCB [11], [12], SU-8 and polyimides [13] have been reported. Surface activation with a combination of temperature and pressure has also been used, i.e., direct bonding [14]. These bonding methods require typically a high curing or process temperature (i.e., $>200^{\circ} \mathrm{C}$ ). The thermal expansion coefficient of $\mathrm{KY}\left(\mathrm{WO}_{4}\right)_{2}\left(8.4-19.8 \mathrm{ppm} / \mathrm{K}\right.$ for respectively the $\mathrm{a}^{*}$ - and c-crystaline axis [15]) is much higher than that of the Mempax substrate used in earlier work [10] $(\mathrm{CTE}=3.3 \mathrm{ppm} / \mathrm{K}$ [16]) causing stress in the bonding interface, which can result in cracks in either the substrate or crystal when elevated bonding temperatures are used. To eliminate the requirement of high process temperature, two UV curable optical adhesives are chosen, Norland Optical Adhesive 81 (NOA81, Norland Products Inc., USA) and Bohle LV740 (UV Adhesive Verifix LV 740, Bhole).

A high planarity of the bonding layer is required to minimize the height difference in the final thin $\mathrm{KY}\left(\mathrm{WO}_{4}\right)_{2}$ layer. A glass bead filled adhesive is mimicked by fabricating pillars with a diameter of $6 \mu \mathrm{m}$ and a spacing $>100 \mu \mathrm{m}$ in a pool area, $12 \times 12 \mathrm{~mm}^{2}$, using standard lithography and fluorine-based reactive ion etching on a $20 \times 20 \mathrm{~mm}^{2} \mathrm{SiO}_{2}$ substrate, as shown in Figure 1. A bulk $\mathrm{KY}\left(\mathrm{WO}_{4}\right)_{2}$ sample with lateral dimension of $10 \times 10 \mathrm{~mm}^{2}$ and $1 \mathrm{~mm}$ thick was then bonded, with one of the UV curable adhesives, on this $\mathrm{SiO}_{2}$ substrate using a Finetech Lambda flip-chip bonder (Finetech $\mathrm{GmbH}, \mathrm{DE}$ ). A gimbal-tool and a large bonding force, $\mathrm{F}=150 \mathrm{~N}$, ensured good contact of the crystal with the pillars, which guarantees a planar bonding layer. The adhesive layer is then cured with flood UV exposure to chemically bond the layers together.

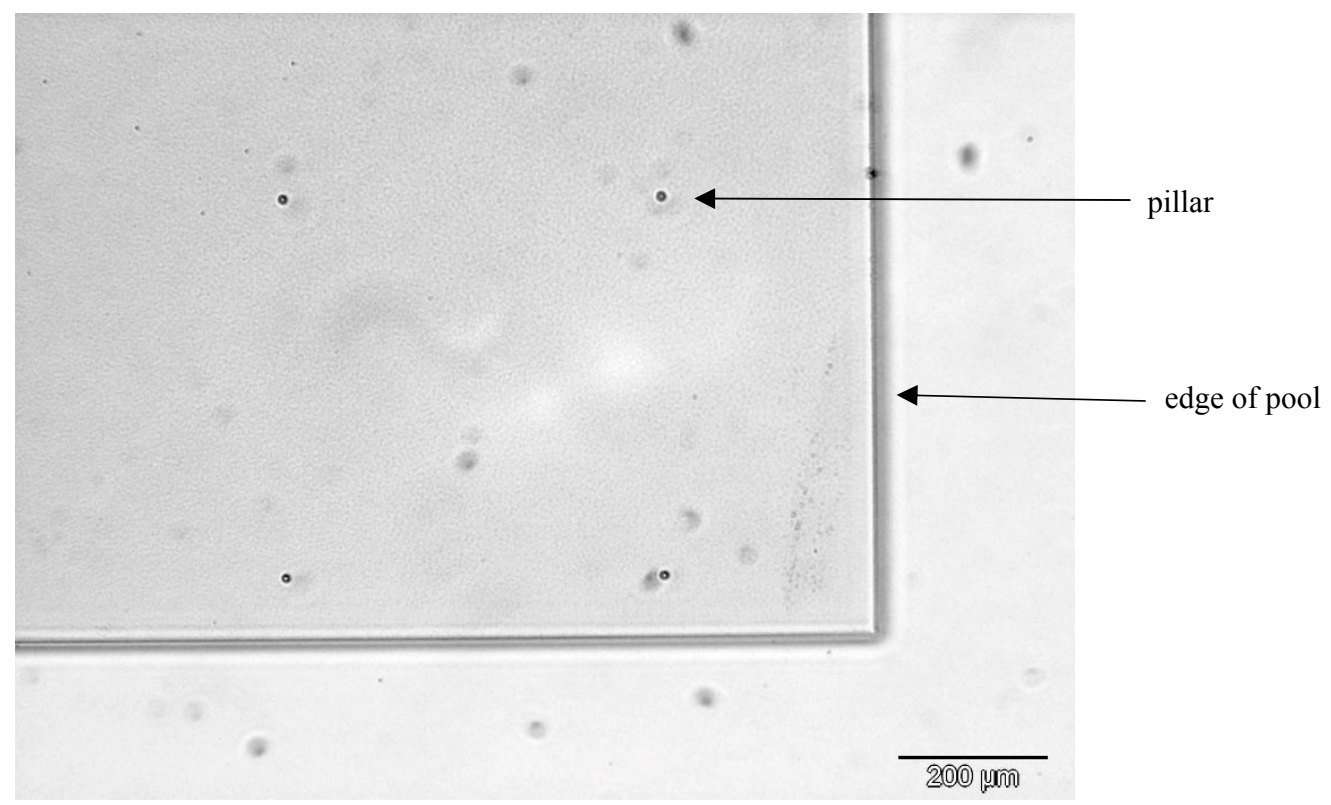

Figure 1: Top view optical microscope image of a corner section of the pool. Inside the pool, pillars with a diameter of $6 \mu \mathrm{m}$ and a spacing of $500 \mu \mathrm{m}$ are clearly visible. The pool is $3 \mu \mathrm{m}$ in depth. 
For the final devices a $\mathrm{KY}\left(\mathrm{WO}_{4}\right)_{2}$ layer thickness of $1 \mu \mathrm{m}$ is needed. Therefore a novel polishing stop was developed. The polishing stop is a layer of hard material that is deposited on the layer stack $\left(\mathrm{KY}\left(\mathrm{WO}_{4}\right)_{2}\right.$ crystal bonded on $\mathrm{SiO}_{2}$ substrate) with the thickness of the desired final layer of $\mathrm{KY}\left(\mathrm{WO}_{4}\right)_{2}$. Deposition of the polishing stop layer (e.g. $\mathrm{Al}_{2} \mathrm{O}_{3}$ or $\mathrm{TiO}_{2}$ ) is done with room temperature pulsed laser deposition (PLD). A schematic representation of the complete stack is shown in Figure 2. The polishing stop will reduce the polishing dramatically when the surface of the polishing stop is reached due to the larger surface area and the larger hardness of the majority of the surface. With this layer, the final thickness can be accurately reached.

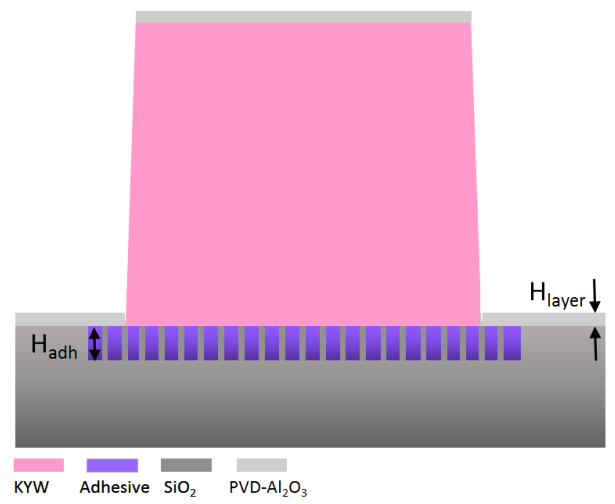

Figure 2. Schematic representation of a bonded $\mathrm{KY}\left(\mathrm{WO}_{4}\right)_{2}$ crystal with $\mathrm{UV}$ adhesive on $\mathrm{SiO}_{2}$ substrate with a pool region with small pillars. A polishing stop of $\mathrm{Al}_{2} \mathrm{O}_{3}$ or $\mathrm{TiO}_{2}$ is deposited with the thickness $\mathrm{H}_{\text {layer }}$ is deposited using pulsed laser deposition. The sizes of the representation are relative because the feature size of the pillars is four orders of magnitude smaller.

\section{THINNING PROCESS}

The bulk KY $\left(\mathrm{WO}_{4}\right)_{2}$ layer has to be thinned from $\sim 1000 \mu \mathrm{m}$ to roughly $1 \mu \mathrm{m}$ to meet the specifications for the final layer. High removal rates cannot be achieved by chemical etching on crystalline $\mathrm{KY}\left(\mathrm{WO}_{4}\right)_{2}$ and therefore a mechanical thinning approach is chosen.
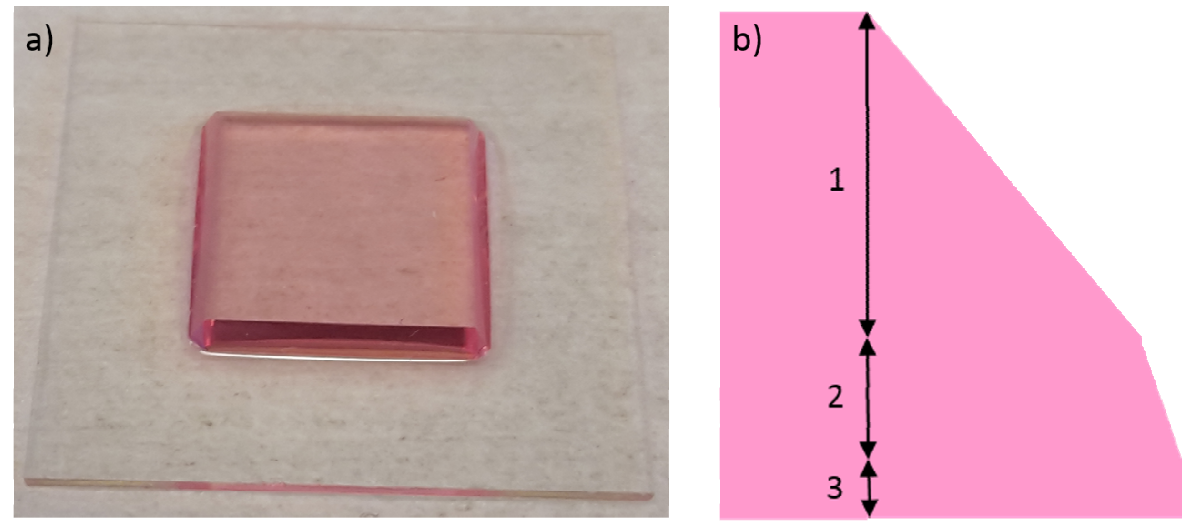

Figure 3. a) $\mathrm{KY}\left(\mathrm{WO}_{4}\right)_{2}$ bulk crystal with beveled edges bonded with $\mathrm{UV}$ curable adhesive on a $\mathrm{SiO}_{2}$ substrate with pillars. b) Schematic representation of a beveled edge. The bevels are made with 3 regions that become gradually steeper in slope. The region 1,2 and 3 are made by using consecutively $\mathrm{SiC}$ paper of 15, 3 and $0.3 \mu \mathrm{m}$ grain size and are made over a vertical length of around 800,150 and $50 \mu \mathrm{m}$ respectively.

The $\mathrm{KY}\left(\mathrm{WO}_{4}\right)_{2}$ crystal has a Mohs' hardness of 4.0-5.0 and in previous thinning experiments chipping of the edges was observed, which causes scratches on the surface of the layer. The chipping was caused by the fact that the edges where rough and vertical, which made them vulnerable during the process. To avoid chipping, the edges have been beveled with a home built beveling tool, which was inspired on the making of polished finished facets on diamonds. Figure 3(a) shows a $\mathrm{KY}\left(\mathrm{WO}_{4}\right)_{2}$ substrate with beveled edges bonded to a $\mathrm{SiO}_{2}$ substrate with a pool with pillars (as described 
above). Those bevels are made in three steps, shown schematically in Fig. 3(b), where the slope becomes steeper closer to the bottom of the sample such that there are no sharp thin parts. Consecutively finer $\mathrm{SiC}$ paper is used such that the sides are not rougher than the surface area, which prevents clustering of lapping or polishing slurry in grooves on the edges.

After the bonding procedure, the layer stack is mounted with low-melting temperature quartz wax (Alcowax, Nikka Seiko, JP) on an ultra-parallel glass plate that can be fixated with vacuum on the polishing jig (PM5 Logitech). Three $\mathrm{KY}\left(\mathrm{WO}_{4}\right)_{2}$ samples are mounted in a triangular configuration, shown in Fig. 4, to assure a high degree of planarity across every individual sample. The planarity of the bond is assured by counting the newton rings and where necessary the height of the layer stack is adjusted before a heavy load is applied during cooling of the wax.

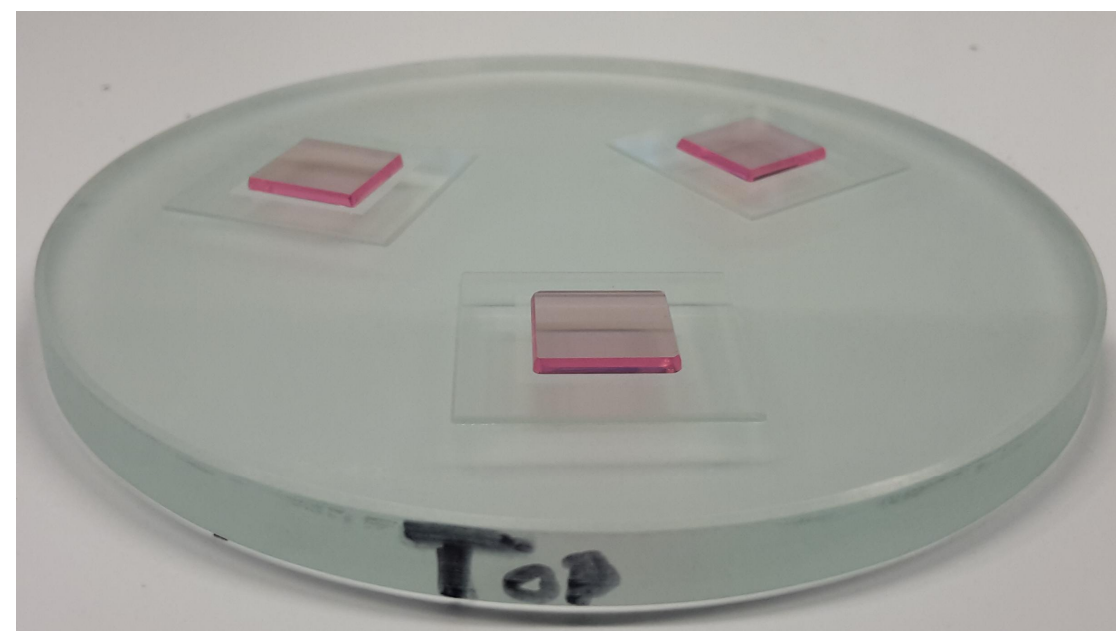

Figure 4. Three layer stacks of $\mathrm{KY}\left(\mathrm{WO}_{4}\right)_{2}$ on $\mathrm{SiO}_{2}$ substrate fixed in a periodic configuration on an ultra-parallel glass plate (with a diameter of $85 \mathrm{~mm}$ ).

For mechanical polishing there are four major factors that can influence the mechanical removal rate, the non-uniformity and the surface quality of the layer. Those factors are the downforce (i.e., load on the layer), kinematics (i.e., speed of the plate), slurry (i.e., flow rate, size, concentration and hardness of the particles), and the ground plate (i.e., hardness and conditioning) [17].

For the thinning process $\mathrm{Al}_{2} \mathrm{O}_{3}$ slurry is used on a cast iron disk as lapping materials, because $\mathrm{Al}_{2} \mathrm{O}_{3}$ particles are harder than $\mathrm{KY}\left(\mathrm{WO}_{4}\right)_{2}$ (Mohs' hardness $\left.\mathrm{Al}_{2} \mathrm{O}_{3} \approx 9.0-9.5, \mathrm{KY}\left(\mathrm{WO}_{4}\right)_{2} \approx 4.0-5.0\right)$ and, in combination with a hard iron plate, it gives a quick removal rate. The lapping stage is divided into three stages: course, intermediate and fine, for which 9,3 and $1 \mu \mathrm{m} \mathrm{Al}{ }_{2} \mathrm{O}_{3}$ particles slurry is used respectively. Not only the particle size is reduced in every consecutive step but also the load on the layer and the rotation speed of the plate are reduced to have more control over the removal rate and less chance on chipping of the edges of the $\mathrm{KY}\left(\mathrm{WO}_{4}\right)_{2}$. After the lapping stage the thickness of the $\mathrm{KY}\left(\mathrm{WO}_{4}\right)_{2}$ layer is reduced from $\sim 1000$ to $\sim 2 \mu \mathrm{m}$ above the polishing stop. The lapping stage is followed by two polishing steps both done on a softer polyurethane disk. First a coarse polish is done with $3 \mu \mathrm{m} \mathrm{CeO}_{2}$ slurry (Mohs' hardness of $\approx 8.0$ ) to quickly remove the traces from the lapping stage. Finally a fine polish is done with $40 \mathrm{~nm} \mathrm{SiO}{ }_{2}$ slurry (Mohs' hardness $\approx 7.0$ ) to get an optically smooth layer with the same thickness as the polishing stop.

\section{RESULTS}

With the presented thinning process, we have achieved layers with a surface tilt of $5.0 \cdot 10^{-3}$ degrees, which is still an order of magnitude larger than the final goal. During the medium lapping stage, defects on the edge of all three samples at two opposing sides were observed. This kind of defects (Fig. 5(a)) were not observed with a similar sample that was bonded on a flat $\mathrm{SiO}_{2}$ substrate (Fig. 5(b)). A possible plausible explanation for those defects is that the pillars act like suspension points. The thin layer $(<50 \mu \mathrm{m})$ bounces into those pillars, like a string, and breaks off due to the too elevated stress on those points. The crystalline axis of the layer were identified using Raman microscopy. The observed defects where parallel to the c-crystallographic axis of the $\mathrm{KY}\left(\mathrm{WO}_{4}\right)_{2}$. Figure 6 shows a schematic representation of the 
$\mathrm{KY}\left(\mathrm{WO}_{4}\right)_{2}$ structure. $\mathrm{KY}\left(\mathrm{WO}_{4}\right)_{2}$ is built from $\mathrm{WO}_{6}$ octahedra joined by means of $\mathrm{WO}_{2} \mathrm{~W}$ double bonds along the $\mathrm{a}^{*}$-axis and WOW single bonds along the c-axis. As it can be clearly seen in Fig. 6, defects are more likely to occur along the caxis. For future experiments the edges of the $\mathrm{KY}\left(\mathrm{WO}_{4}\right)_{2}$ have to be beveled to avoid chipping, the thin layers $(<50 \mu \mathrm{m})$ have to be surrounded by a layer of adhesive to give protection against the lapping particles and the effect of the size and spacing of the pillars has to be further investigated.
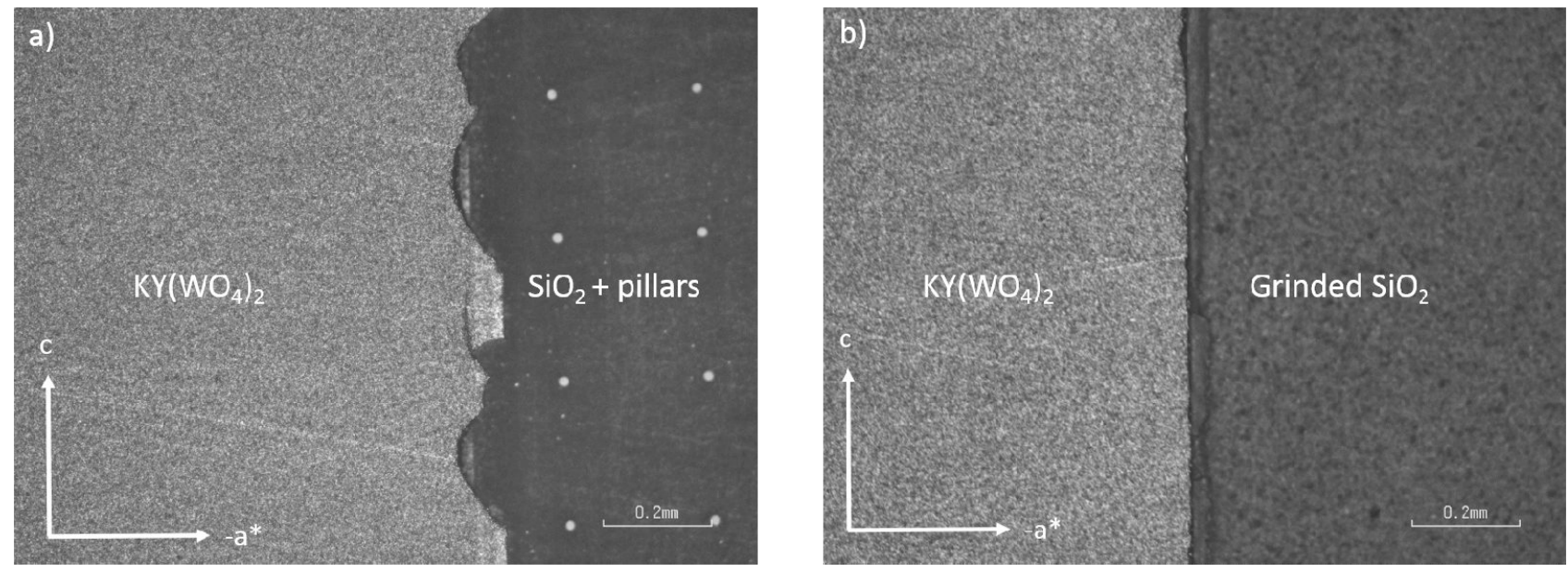

Figure 5. Both samples bonded with UV curable adhesive on a) a $\mathrm{SiO}_{2}$ pillar substrate with pillars with a diameter of $18 \mu \mathrm{m}$ and $250 \mu \mathrm{m}$ separation, b) a flat grinded $\mathrm{SiO}_{2}$ substrate. The c-crystallographic axis is indicated, as identified by Raman spectroscopy.

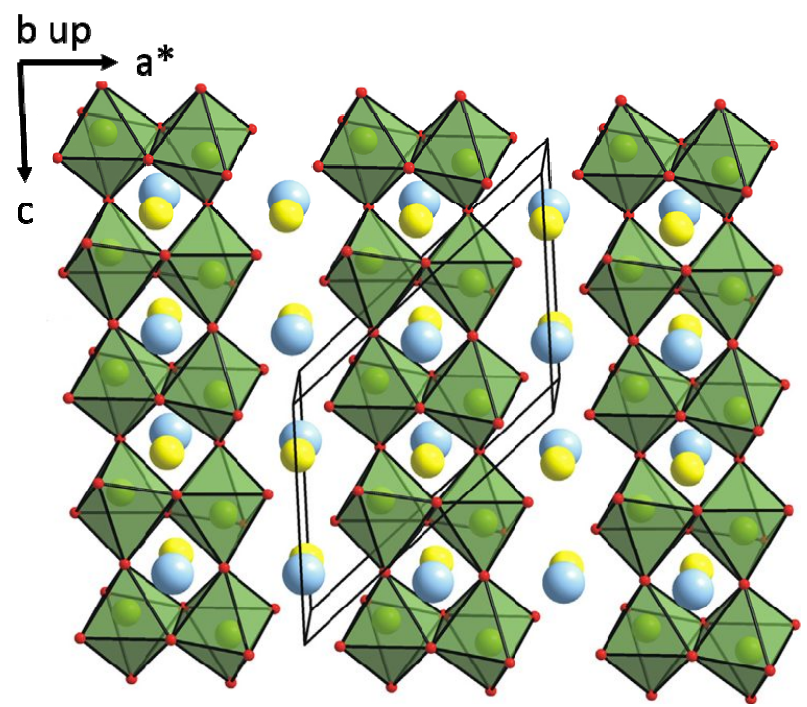

Figure 6. View of the $\mathrm{KY}\left(\mathrm{WO}_{4}\right)_{2}$ structure approximately along the $\mathrm{b}$ axis. Atoms are shown are shown as spheres of the following color: potassium (light blue), yttrium (yellow), tungsten (green) and oxygen (red). Rows of corner and edges sharing $\mathrm{WO}_{6}$ octrahedra are emphasized [18].

Despite the appearance of these defects, which are currently under investigation, the planarity of the sample bonded onto the pillar spacers (surface tilt $5.0 \cdot 10^{-3}$ degrees) achieved better planarity compared to a sample bonded on a flat $\mathrm{SiO}_{2}$ substrate (surface tilt $1.5 \cdot 10^{-2}$ degrees) although both samples followed identical polishing process. Future work have to be done to get this surface tilt an order of magnitude smaller to ensure single mode operation over the whole chip length. Unfortunately the room temperature $\mathrm{PLD} \mathrm{Al}_{2} \mathrm{O}_{3}$ could not be demonstrated because the adhesion was not strong enough with the $\mathrm{SiO}_{2}$ substrate and it is ongoing work. 


\section{CONCLUSION}

A thinning procedure to integrate $\mathrm{KY}\left(\mathrm{WO}_{4}\right)_{2}$ layers onto $\mathrm{SiO}_{2}$ substrate have been developed. For a sample bonded on a substrate with pillar spacers a surface tilt of $5.0 \cdot 10^{-3}$ degrees was fabricated whereas a sample bonded on a flat substrate, and thinned with the same procedure, had a surface tilt of $1.5 \cdot 10^{-2}$ degrees. This shows that bonding on a pillar structure gives a better planarity of the layer. Future work has to be done to avoid defects on the edges due to the supporting pillars and the adhesion of the room temperature PLD deposited $\mathrm{Al}_{2} \mathrm{O}_{3}$ polishing stop has to be improved to be able to achieve a thin optical smooth $\mathrm{KY}\left(\mathrm{WO}_{4}\right)_{2}$ layer.

\section{ACKNOWLEDGMENT}

The authors acknowledge support from the European Research Council Consolidator Grant (project number 648978) under the project abbreviation RENOS.

\section{REFERENCES}

[1] Kaminskii, A. A., Konstantinova, A. F., Orekhova, V. P., Butashin, A. V, Klevtsova, R. F. and Pavlyuk, A. A., "Optical and nonlinear laser properties of the $\chi(3)$-active monoclinic $\alpha-\mathrm{KY}\left(\mathrm{WO}_{4}\right)_{2}$ crystals," Crystallogr. Reports 46(4), 665-672 (2001).

[2] Pujol, M. C., Mateos, X., Solé, R., Massons, J., Gavaldà, J., Solans, X., Díaz, F. and Aguiló, M., "Structure, crystal growth and physical anisotropy of $\mathrm{KYb}\left(\mathrm{WO}_{4}\right)_{2}$, a new laser matrix," J. Appl. Crystallogr. 35(1), 108-112 (2002).

[3] Yong, Y.-S., Aravazhi, S., Vázquez-Córdova, S. A., Carjaval, J. J., Díaz, F., Herek, J. L., García-Blanco, S. M. and Pollnau, M., "Temperature-dependent absorption and emission of potassium double tungstates with high ytterbium content.," Opt. Express 24(23), 26825-26837 (2016).

[4] Geskus, D., Aravazhi, S., García-Blanco, S. M. and Pollnau, M., "Giant optical gain in a rare-earth-ion-doped microstructure," Adv. Mater. 24(10), 22-25 (2012).

[5] Geskus, D., Aravazhi, S., Wörhoff, K. and Pollnau, M., "High-power, broadly tunable, and low-quantum-defect $\mathrm{KGd}_{1-\mathrm{x}} \mathrm{Lu}_{\mathrm{x}}\left(\mathrm{WO}_{4}\right)_{2}: \mathrm{Yb}^{3+}$ channel waveguide lasers.," Opt. Express 18(25), 26107-26112 (2010).

[6] Geskus, D., Aravazhi, S., Grivas, C., Wörhoff, K. and Pollnau, M., "Microstructured $\mathrm{KY}\left(\mathrm{WO}_{4}\right)_{2}: \mathrm{Gd}^{3+}+, \mathrm{Lu}^{3+}$, $\mathrm{Yb}^{3+}$ channel waveguide laser," Opt. Express 18(9), 8853 (2010).

[7] van Dalfsen, K., Aravazhi, S., Grivas, C., García-Blanco, S. M. and Pollnau, M., "Thulium channel waveguide laser in a monoclinic double tungstate with 70\% slope efficiency," Opt. Lett. 37(5), 887 (2012).

[8] Aravazhi, S., Geskus, D., van Dalfsen, K., Vázquez-Córdova, S. A., Grivas, C., Griebner, U., García-Blanco, S. M. and Pollnau, M., "Engineering lattice matching, doping level, and optical properties of $\mathrm{KY}\left(\mathrm{WO}_{4}\right)_{2}: \mathrm{Gd}$, $\mathrm{Lu}$, Yb layers for a cladding-side-pumped channel waveguide laser,” Appl. Phys. B 111(3), 433-446 (2013).

[9] Sefunc, M. A., Segerink, F. and Garcia-Blanco, S., "High index contrast potassium double tungstate waveguides towards efficient rare-earth ion amplification on-chip," Proc. SPIE 9365, 93650P1-6 (2015).

[10] van Emmerik, C. I., Martinussen, S. M., Mu, J., Sefünç, M. A., Dijkstra, M. and García-Blanco, S. M., "Toward highly confined potassium double tungstate waveguides for laser applications," Proc. IEEE Phot. Soc. Benelux 21, 163-166 (2016).

[11] Christiaens, I. and Roelkens, G., “Adhesive wafer bonding with Benzocyclobutene,” J. Light. Technol. 1(11), 17 (2004).

[12] Keyvaninia, S., Muneeb, M., Stankovic, S., Van Veldhoven, P. J., Van Thourhout, D. and Roelkens, G., "Ultrathin DVS-BCB adhesive bonding of III-V wafers, dies and multiple dies to a patterned silicon-on-insulator substrate," Opt. Mater. Express 3(1), 35-46 (2013).

[13] Yacobi, B. G., Martin, S., Davis, K., Hudson, A. and Hubert, M., "Adhesive bonding in microelectronics and photonics," J. Appl. Phys. 91(10 I), 6227-6262 (2002).

[14] Talneau, A., Pantzas, K., Durnez, A., Patriarche, G., Alamarguy, D. and Le Bourhis, E., "An ultra-thin $\mathrm{SiO}_{2}$ ALD layer for void-free bonding of III-V material on silicon," Microelectron. Eng. 162, 40-44 (2016).

[15] Loiko, P. A., Yumashev, K. V., Kuleshov, N. V., Rachkovskaya, G. E. and Pavlyuk, A. A., "Detailed characterization of thermal expansion tensor in monoclinic $\mathrm{KRe}\left(\mathrm{WO}_{4}\right)_{2}$ (where $\left.\mathrm{Re}=\mathrm{Gd}, \mathrm{Y}, \mathrm{Lu}, \mathrm{Yb}\right)$," Opt. Mater. 34(1), 23-26 (2011).

[16] "MEMpax ${ }^{\circledR}$ Ultra-Thin Borosilicate Glass: SCHOTT Advanced Optics | SCHOTT AG.", 
$<$ http://www.schott.com/advanced_optics/english/products/optical-materials/thinglass/mempax/index.html\#block362966> (16 January 2018 ).

[17] Zhao, D. and Lu, X., "Chemical mechanical polishing: Theory and experiment," Friction 1(4), 306-326 (2013).

[18] Schwung, S., Enseling, D., Wesemann, V., Rytz, D., Heying, B., Rodewald, U. C., Gerke, B., Niehaus, O., Pöttgen, R. and Jüstel, T., "KYW $\mathrm{O}_{8}:$ Eu $^{3+}$ - A closer look on its photo luminescence and," J. Lumin. 159, 251257 (2014). 